\title{
Rules of English Spelling and the Choice to Use $t$ or $s$ in Shun-Words: A Wink at Anglophone Cameroonian Students
}

\author{
Blasius Achiri-Taboh ${ }^{1}$ \\ ${ }^{1}$ Department of Linguistics, UNESCO Building, Room 220, University of Buea, PO Box 63, Buea, SW Region, \\ Cameroon \\ Correspondence: Blasius Achiri-Taboh, Department of Linguistics, UNESCO Building, Room 220, University of \\ Buea, PO Box 63, Buea, SW Region, Cameroon
}

Received: June 13, 2016

Accepted: June 15, 2018

Online Published: June 18, 2018

doi:10.5430/elr.v7n2p37

URL: https://doi.org/10.5430/elr.v7n2p37

\begin{abstract}
Although English spelling has been of significant interest to scholars since the 1950s, it has remained a major problem even to native speakers. One peculiar problem with it is the spelling variation of the noun formation suffix often represented in discourse as "shun," mainly between -tion and -sion. Current textbooks of English grammar have generally not discussed rules of its spelling with either form, even though they do many others. However, following online resources, conflicting on how to spell it are in current debate, with two main schools of thought that each fall in line with one of two approaches that can be called the "word-based model" and the "base-word model." In Achiri-Taboh (2018), I have shown that, in writing down words that end with "shun," the base-word model is to be preferred, presenting argument for a synchronic rule following the base-word model with seven conditions to warrant the use of -sion as opposed to -tion, albeit with exceptions. Following current debates and a test of Anglophone Cameroonian students for their spelling preferences, the present study establishes the problem as global and compelling enough, especially for Non-Native users and learners of English, to warrant an address in grammar textbooks by means of available recourses like the recent base-word-based rule. The study also demonstrates that the prevalence of the problem actually stems from the lack of readily available spelling rules in grammar textbooks, and that there is a need for further research on spelling rules in English.
\end{abstract}

Keywords: English spelling, shun-word, BWB rule, spelling variation, spelling rule, grammar textbook

\section{Introduction}

Presumably, although it might controversially be asked, as in Andrew Woods (2004), if society should place so much value on correct spelling, users of the English language around the world generally agree that appropriate spelling is important for appropriate written communication and/or correspondence. For example, Bilchik and Cole (2012) state that "on the topic of written communications, be aware that how you write reflects on you. Poor spelling and grammar can quickly spoil a professional image." Richards (2002: 186) also point out that "it is easy to spoil a piece of written work with poor spelling [and that] some people will not take what you have written seriously if you haven't spelled it correctly." Yet, English spelling is not so easy a thing to grapple with. In LearningExpress (2006: 15), it is written:

In the English language, if you simply wrote words the way they sound, you'd come up with some very peculiar spellings. If you tried to sound out every word and pronounce it exactly the way it's written, you'd come up with some pretty odd pronunciations too.

Thus, in current English studies, an intriguing question frequently recurs: why are English words not always written the way they are spoken? Classic examples of this mismatch include the use of digraphs like <ph> for /f/ and <gm> for $/ \mathrm{m} /$ as in 'diaphragm' (Achiri-Taboh 2017). Looking at the digraph $\langle\mathrm{ph}\rangle$, for example, "in his column ['Trivia'] for April 27, 2004 (The Orange County Register, Santa Ana, California) ... [L. M. Boyd] writes, 'Is there any word in English, besides "shepherd," that contains a "ph" not pronounced like an "f"? Doubt it"” (Kaye, 2006: 54). In other words, digraphs (and trigraphs) are combinations of letters not pronounced the way they appear.

English spelling has been of significant interest to scholars since the 1950s (see, for example, West 1955 and West 1965). In fact, as West (1965) observes, it is a major problem even to native speakers. Thus, as I point out in Achiri-Taboh (2018: 1), one peculiar problem about it is with the spelling variation of the noun formation suffix 
often represented in discourse as "shun," underlined here in words like fraction, dictation, equation, and persuasion (with a $t$-form) and extension, collision, and expression (with an $s$-form). (Note 1) In most of the cases of words that end with the suffix in English, the latter is spelled either as -tion or -sion (Harnew 2007). Although other spellings of it are available (viz, -cian (for professions: beautician, musician, and physician), -sian (for origins or nationality: Asian, Caucasian), -tian (also for origin or nationality: Lilliputian, Venetian (but note US dietitian as a profession)), and some arbitrary ones including -xion (complexion, connexion, crucifixion), -cion (coercion, suspicion), -shion (cushion, fashion), and -cean (crustacean, ocean)), those that name professions and origins are usually straightforwardly predictable, and the arbitrary ones are fewer and learners and other users can be led to learn them by heart; as Harnew points out, cushion and fashion are the only two common English words with the ending spelled -shion. So, as I note in Achiri-Taboh (2018: 2), the problem is mainly with the -tion/-sion variation. An important question therefore is how to decide on these two variants in the spelling of a shun-word, and I presume this is a serious problem for students of English around the world on a daily basis. Specifically, the fact that the suffix exhibits an orthographic alternation is clearly intriguing, especially given that many other suffixes in English do not exhibit changes (with respect to their environment) as can be seen in Table 1 with examples from LearningExpress (2006: 49).

Table 1. Many other suffixes in English do not exhibit orthographic alternations

\begin{tabular}{|c|c|}
\hline Suffix & Sample words \\
\hline -ment & comportment, indictment \\
\hline -ist & archaeologist, biologist \\
\hline -ism & absolutism, altruism \\
\hline -ity & sanity, scarcity \\
\hline$-o \log y$ & morphology, theology, biology \\
\hline -escence & Acquiescence \\
\hline$-\mathbf{y}$, ary & flattery, commentary \\
\hline -able & dependable, believable \\
\hline -ic & eccentric, optimistic \\
\hline -ian & politician, statistician \\
\hline -ile & reptile, fertile \\
\hline -ious & delicious, superstitious \\
\hline -ive & productive, expensive \\
\hline -less & senseless, painless \\
\hline -ize & sensitize, monopolize \\
\hline -ate & communicate, implicate \\
\hline -ify & purify, magnify \\
\hline
\end{tabular}

In Achiri-Taboh (2018), I present argument for a base-word-based (BWB) rule for the spelling of shun-words with as many as seven conditions to warrant the use of -sion in words like abrasion and secession as opposed to -tion in words like action and separation, albeit with exceptions. Let us summarize this rule as follows:

(1) The Base-Word-Based (BWB) rule for spelling "shun":

Use -tion everywhere except when $\mathrm{X}(\mathrm{X}=$ any of the 7 conditions (Note 2))

The sheer number of conditions to follow for the rule in (1) plus the fact that exceptions abound to guard against actually attest to the severity of the problem with the spelling of shun-words.

In the present study, I neither attempt to do a critique of the BWB rule nor do I propose a simpler answer to the question on how to choose between the two forms. My aim is rather to establish the problem as global and compelling enough especially from a Non-Native Speaking user/learner's perspective to warrant being addressed in grammar textbooks by means of available recourses like the proposed BWB rule. Specifically, considering current debates, and with field experience from Cameroon where I come from, I demonstrate (a) that spellers generally get confused with the spelling of shun-words with either the -tion or -sion variant, although words with spellings of 
"shun" other than the -tion and -sion variants do not constitute a serious problem to them as they are either straightforwardly predictable or few enough to be learned by heart; (b) that given specific rules to follow, there can be great improvement on the spelling of shun-words; and (c) that there is a need for further research on spelling rules in English. As is evident that the article places emphasis on the question why English spelling is a big problem to so many people around the world, I also provide a brief historical perspective of the problem.

\section{The -tion/-sion Variation among Anglophone Cameroonian Students}

Over a number of years observing writings of students at the University of Buea, in Cameroon, I have noted that many students get confused with the spelling of shun-words with either the -tion or -sion variant of the suffix wherever they occur, often using the $t$-form where they should use the $s$-form, and vice versa, the former occurring ever more often than the latter. This is demonstrated in Figure 1 below by means of an extract from a student's script.

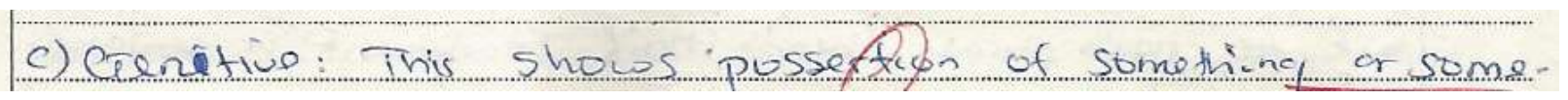

Figure 1. Sample student writing with a misspelled shun-word

The problem can clearly be seen in the results of a spelling test I designed and conducted, codenamed "concentration test," to see how students perform at the spelling of shun-words as opposed to other complex words with suffixes.

\subsection{The Test}

The test is as follows - it is codenamed "concentration test" for reasons to be made clear later in Section 2.2:

\section{Concentration test}

This is a concentration test. While listening carefully to understand, write down this passage. Write all the words in full, and beware that the passage will be read only once. You will then have one question to answer in just 2 minutes. Do not identify yourself, as this is not part of your continuous assessment, but do indicate your towns of origin and residence before you begin.

Town of origin (place of birth): Town of residence

Some members of the College Administration who were involved in the selection and distribution of admission letters to candidates with proper qualification had secretly been issuing admissions without due permission. When the Board of Directors started planning to set up a commission of inquisition for the investigation of the apparent subversion, the Dean readily tendered his resignation letter to the Board. The impression one gets from the Dean's position is that he had acted in pretension, and seems to have something to hide, although he insists that his decision is not an expression of guilt, but rather a devotion to his duties. One of the directors has wondered why he should resign in this fashion, and has described his decision as derision and an aversion to justice. He said that the occasion did not carry any compulsion for him to resign, and so his conclusion has come with much concision. He ended by putting stress on the idea that all other problems of the collage should compulsorily be identified, and that it must be purified of its insanities. "The goal is achievable if we receive full cooperation from everyone," he said, "and every fish in the ocean should detest the great white,"

Q: In your opinion, why did the Dean resign?

As the reader can see, the passage is made up of 10 shun-words with the $t$-form, 10 others with the (single) $s$-form, and 6 of them with double-s. The words fashion and ocean with the same ending each spelled differently were included for the purpose of checking students' ability to recognize the minority set of shun-words with assorted spellings other than those that take -tion or -sion and whether or not they knew the different spellings of "shun" in those minority words. Other classes of word in pairs including planning and putting, achievable and receive, readily and compulsorily, duties and insanities, and identified and purified, all of which require special spelling variations from their base-words were added to check whether students do actually learn and follow rules of spelling English words - each type of word appeared twice so that the students could be checked for consistency in their spelling preferences. 


\subsection{Sampling and Method of Administration}

Final year students of the Department of Linguistics - 84 in all who were present in class that morning - were selected for the test. The choice was motivated, firstly by the ease of accessibility to the students, since I am a lecturer in the Department; secondly, being students of Linguistics, they were suitable for it, having gone through two Use of English courses in addition, and were expected to have perfected their spelling skills. I considered them a microcosm of the entire body of Anglophone Cameroonian students, as a large majority of them (49) originate and (at the time of the study) were normally resident in different places all over Anglophone West Cameroon, that is, the Northwest and Southwest Regions of Cameroon, judging from the indications of their towns of birth and residence; 16 of them were born in West Cameroon but normally resident in towns across Francophone East Cameroon; 11 were born in East Cameroon but normally resident in West Cameroon; and 8 were born in East Cameroon and normally reside there.

The students - hence participants (who were tested at the beginning of the first semester of the 2014/2015 academic year) were made to believe that they were being tested for their levels of concentration, that is, their ability to follow lectures and take down notes in the process, and not for any assessment. As they were not placed under any exam condition, the claim that they were being tested for concentration was in order to circumvent any incidence of panic and (unnecessary) cheating and to be able to secure (relatively) natural results. The passage was read once, slowly enough though for the participants to have the best chance to get every word clearly. The question to be answered in two minutes thereafter was just to justify the supposed reason for the test, and so had nothing to do with the study.

\subsection{Statistics of Test Results}

The statistics of results of the test are placed in Table 2 below.

Table 2. Quantitative statistical data from the spelling test

\section{Relevant word type + number of entries}

Range of scores

$\begin{array}{lllllllllll}10 & 09 & 08 & 07 & 06 & 05 & 04 & 03 & 02 & 01 & 00\end{array}$

Number of participants per score

\begin{tabular}{|c|c|c|c|c|c|c|c|c|c|c|c|}
\hline -tion words: 10 & 47 & 30 & 04 & 03 & & & & & & & \\
\hline -sion words: 10 & 06 & 11 & 19 & 12 & 09 & 18 & 04 & 02 & 02 & 01 & \\
\hline -ssion words: 6 & & & & & 59 & 08 & 08 & 03 & 06 & & \\
\hline $\begin{array}{l}\text { aversion, concision, derision - (infrequent words) } \\
\text { with -sion: } 3\end{array}$ & & & & & & & & 16 & 35 & 24 & 09 \\
\hline -ss- words with the ending -mission: 4 & & & & & & & 63 & 05 & 08 & 04 & 04 \\
\hline -ss- words with the ending -pression: 2 & & & & & & & & & 80 & 04 & \\
\hline $\begin{array}{l}\text {-tion words with addition of epenthetic [I] or }[\mathrm{e}] \\
\text { (viz., administration, qualification, inquisition, } \\
\text { resignation, and position): } 5\end{array}$ & & & & & & & 84 & & & & \\
\hline $\begin{array}{l}\text {-tion words with - } C+\text { ate base ending where } C \\
\text { stands for any consonant (viz., investigation and } \\
\text { cooperation): } 2\end{array}$ & & & & & & & & & 84 & & \\
\hline fashion, ocean - with other spellings: 2 & & & & & & & & & 84 & & \\
\hline planning, putting - with consonant doubling: 2 & & & & & & & & & 67 & 06 & 11 \\
\hline $\begin{array}{l}\text { achievable, receive - words under the } i \text { before } e \\
\text { rule: } 2\end{array}$ & & & & & & & & & 71 & 08 & 05 \\
\hline compulsorily, readily - changing $y$ to $i: 2$ & & & & & & & & & 82 & & 02 \\
\hline duties, insanities - changing $y$ to $i: 2$ & & & & & & & & & 84 & & \\
\hline
\end{tabular}

As the reader can see, the participants generally did better in the spelling of words with the $t$-form than in those with the $s$ - (or $s s$-) form. Thus, for the 10 words that take the $t$-form, 47 of the 84 participants scored 10/10, 30 scored 9/10, 4 scored 8/10, and 3 scored 7/10 (i.e., none scored below 7/10); for the 10 that take the $s$-form, 6 scored 10/10, 11 
scored 9/10, 19 scored 8/10, 12 scored 7/10, and the rest scored below -9 scored 6/10, 18 scored 5/10, and 9 scored below 5/10; for the 6 that take the $s s$-form, 59 scored 6/6, 8 scored 5/6, 8 scored 4/6, 3 scored 3/6, and 6 scored 2/6.

Based on the motivation for the sample population, we can assume that these results generally confirm the observation that Anglophone Cameroonian students face serious problems with the spelling variation in the addition of the noun formation suffix under discussion. Some specific results make the observation compelling. For 3 words that take the $s$-form which I judge to be less-frequently used by the participants, namely, aversion, concision, and derision, only 16 of the 84 spelled the suffix in all three instances correctly; 35 scored 2/3, 24 scored 1/3, and 9 had none of the three words correctly spelled with the $s$-form. Going down to details, only 33 of the 84 participants spelled the word 'concision', for example, with the correct $s$-form, and of the remainder, 40 spelled it with $t$ and 11 did so with -ss-. The passage contains 4 ss-words with the ending -mission, namely, admission, admissions, permission, and commission, and 2 with the ending -pression, namely, impression and expression; for the former, only 63 of the 84 participants had all 4 instances correct, while for the latter, 80 had all 2 correct, the others thus spelling the $s s$-form wrongly either with $t$ or with a single-s.

In summary, the statistical details of the spelling test results of Anglophone Cameroonian students specifically demonstrate that, as already pointed out, in the spelling of the noun formation suffix "shun" in its two main complementary distributive forms in different words is a serious problem for spellers. One crucial part of the statistics worthy of noting at this time, though not reflected in the table for expository convenience, is that the participants generally did not have a problem with spelling the base-words preceding "shun." Specifically, apart from the word concision which up to 69 participants spelled with $s$ for the second $c$, only 9 of them misspelled some of the base-words. (for example, 1 spelled concision with ie after $c$ perhaps influenced by the popular $i$ before $e$ rule, while 2 spelled selection with double-l, perhaps following a pattern with collection; 2 spelled derision with double- $r ; 3$ spelled occasion with a single- $c, 1$ with a single- $c$ followed by $a i$ and another with double- $c$ followed by $a i$.) Besides, as we see in the next section, participants generally had complex words with available spelling rules correctly spelled. This fact, in itself, shows that the -tion/-sion alternation is a real problem. Although as an ET reviewer suggests, the spelling preferences of Anglophone Cameroonian students might not be the basis of decisions about the best linguistic analysis of the "-tion/-sion" situation, note that the salient observation comes amidst current conflicting online debates on how best to spell shun-words - see dailywritingtips.com, howtospell.co.uk, spellzone.com, and skillsworkshop.org among others. Indeed, this suggests that the problem with the spelling of the suffix has been observed elsewhere, at least informally, and the fact actually establishes it as a global problem and thus real, with the case of Anglophone Cameroonian students being a vivid illustration of it. I return to further details of the results in Section 3 below.

\section{The Need for Further Research on Spelling Rules in English}

In this section, I demonstrate that, in writing, users of English can do much better at spelling English words if rules are readily available to follow. As Adams-Gordon (2010: 12) points out, "the greatest force which impedes the learning of spelling is a lack of interest or presence of undesirable attitudes towards instruction." Such a force may set in and afflict the learning of spelling once there are no rules to mitigate the yoke of memorization.

The problem under consideration is certainly a global one. With it and many other spelling problems, one question that often recurs, as on website fora like oxfordtoday.ox.ac.uk, quora.com, and theconversation.com, is: why is English spelling posing such a big problem to so many people, and how can we thwart it? As is well documented (see Allen, 2002; Huddleston \& Pullum, 2005; Seely, 2005; Upward \& Davidson, 2011 among others), the answer to the question of English spelling is linked directly to linguistic history. Thus, "relevant features of the spelling system were established several centuries ago, and may reflect pronunciations that are no longer current for all or some varieties of English" (Huddleston \& Pullum, 2005: 269). Seely (2005: 209) assesses the problem as follows:

Unlike Italian and other so-called "phonetically spelled" languages, English cannot easily have a direct correspondence between sounds and letters. There are over forty sounds in English, far more than in Italian, and we only have the same twenty-six letters in the alphabet. So we have to combine letters in different ways to represent the "missing" sounds. To do this, we rely on a series of conventions. These developed over a period of history during which the vocabulary of English and its pronunciation were both also developing. Words came into English from many other languages and many retained their original spelling but changed their pronunciation. Other imports came from languages with a different writing system and were written down by travellers and merchants in the best way they could. In all this richness of vocabulary and linguistic vitality there has never been a consistent attempt to reform the whole spelling system. 
Thus, as Akundayo (2014: 4) points out, a lot of criticism has been directed against the English spelling system since Middle English. (Note 3) Also see Akundayo (2014: 6) for major attempts at reforming English spelling within the last 500 year, largely unsuccessful though. Seely concludes his assessment by saying:

So we are stuck with a spelling system that is far from ideal and the best we can do is to device workable strategies to help us spell better... There are ways of getting a grip on spelling generally and there are specific rules which can be learned.

In other words, as Taylor (1981), for example, makes the case, English spelling is by no means as unsystematic as many would see it to be. Thus, according to Crystal (2005: 214), the English language is about 75\% regular. However, the about $25 \%$ of irregularity is $25 \%$ too much for a language so widely dependent upon on a daily basis, and I believe this is the basis for the question why English words are not always written the way they are spoken. Thus, although Crystal also notes that "the 400 or so irregular spellings are largely among the most frequently used words in the language, and this promotes a strong impression of irregularity," 400 regularly used irregularly spelled words certainly constitute a serious menace to users, raising the need for further research on spelling rules in English in the absence of workable spelling reforms.

As has become clear by now, although there exist other spelling varieties of the shun-suffix, the problem is mainly with the -tion/-sion variation, as the other varieties, especially those that name professions and origins are usually straightforwardly predictable, and the arbitrary ones are fewer and can be learned by heart. Thus, one assumption to make is that one of the forms is basic and the other derived, such that rules for using one form as opposed to the other can be formulated. According to the BWB rule, the $t$-form is basic. One thing that corroborates this position is the fact that learners always inadvertently use -tion where they should use -sion as demonstrated in Figure 1. This can also easily be seen if we go back to the statistics of the test results. All 84 participants scored at least 7/10 in the spelling of the $t$-form words, with 47 of them scoring $10 / 10$ and 30 scoring 9/10, as against only 6 of them scoring $10 / 10$ and 11 scoring $9 / 10$, for the $s$-form words. Note again that only 33 participants spelled the suffix on the word concision with the correct $s$-form, and of the remainder, up to 40 spelled it with $t$, what suggests that they generally employ the $t$-form first and then try to judge its validity. Thus, the $t$-form is more likely to be used each time a word with the suffix features, what makes it likely to be the base form. In other words, we can say that it is the $t$-form that is generally used, while the $s$-form is restricted to specific environments in corroboration of the BWB rule.

With the above reasoning, it is clear that the problem that arises from the spelling of "shun" on words that take the suffix or that end thus comes as a result of a lack of rules for its spelling. In other words, spellers may actually get confused in the spelling of shun-words because they are not readily exposed to rules to follow and have to depend largely on memorization. Seely (2005: 211), for example, points out and suggests that

A typical problem area is the double or single letters that occur in words like accommodation, imitate, and professional. You could try to learn the whole list of problem words by heart. [...] If you wish to remember a visual pattern it is important that you should see it. When you are trying to learn a spelling that causes problems, a well-known method is look-cover-write-check .... With a problem word this process should be repeated at increasing intervals until you are confident that it is fixed in your mind.

The need for specific spelling rules in English is again confirmed by the statistics of the spelling test results in Table 2 where paricipants can be seen to master existing spelling rules as presented in English grammar textbooks. As the statistics show, they are generally good at spelling words that exhibit spelling variation due to affixation where rules are readily available to follow. The established rules for which participants were tested - see, for example Perrin (1990), Seely (2005), and Shepheard (2001) among others - include (1) the doubling of the final consonant before adding a suffix (like -ing or -ed) if the final syllable of the base-word receives stress and ends with a short vowel and a single consonant; (2) the placing of $i$ before $e$ in some words with the (long) /i:/ sound except before $c$ (widely seen as the most popular spelling rule); and (3) the changing of final $-y$ to $-i$ after a consonant before adding -ly, -es or -ed. The indication that spellers have to depend on memorization to spell certain types of word in the absence of guiding rules implies that patterns of spelling certain other specific words may naturally unveil themselves to spellers. Thus, it can also be observed that spellers are generally good at spelling words whose spellings are predicated upon semantic indicators. An example is the spelling of the shun-ending as -cian in words like musician, beautician and dietician which name professions, although such words did not feature in the relevant spelling test.

Finally, as I point out in Achiri-Taboh (2018: 4), shun-words that exhibit epenthesis (between the base-word and the suffix) require the suffix to be spelled with $t$-examples for which participants were tested include administration, qualification, inquisition, resignation, and position. I also observe in Achiri-Taboh (2018: 5) that there exist other shun-words whose base-words bear a final syllable vowel that generally patterns like an epenthetic [eI] and so 
triggers the use of the $t$-form. Two examples participants were tested on are investigation and cooperation. We can observe here that spellers generally understand the effect of epenthesis on the choice to use $t$ or $s$ in the spelling of shun-words, as all 84 participants had all the 7 epenthetic shun-words used in the text correctly spelled with -tion.

As pointed out already, apart from informal online debates on how to spell "shun" either by considering the spelling of the word that contains it as a single whole (as with diction, mission and station) and then looking at its internal structure for clues, or by considering the word as a combination of a base-word and a suffix (as with dictation and permission) and then examining the base-word ending for clues, current English grammar textbooks have generally not discussed rules for the spelling of shun-words. For example, in English grammar by John Shepheard (2001), where whole chapters are devoted to affixation and spelling, a treatment of "shun" is conspicuously absent. If the problem with the spelling of shun-words is a pressing one and truly global in nature, then the BWB rule stated in (1) above is a worthwhile attempt at satisfying a burning need. The fact that participants are seen to do well at spelling words where patterns and established rules are readily available to follow is testimony of this need and that spellers do actually learn spelling rules and follow them. Thus, as I point out in Achiri-Taboh (2018: 6), although the BWB rule includes as many as seven conditions, once spellers get used to the idea of picking out the base-words from complex shun-words and considering their endings, it becomes easy to establish a connection between any of the conditions and -sion with respect to Pinker's (1999: 269) Words-and-Rules Theory.

\section{Remarks and Conclusions}

Against the backdrop that English spelling has remained a major problem even to native speakers even though it has been of significant interest to scholars since the 1950s, this paper has examined the pervasiveness of a spelling problem of a peculiar type concerning the spelling variation of the noun formation suffix often represented in discourse as "shun," mainly between -tion and -sion. As indicated above, current textbooks of English grammar are yet to discuss rules of the spelling of the suffix with either form. Following online resources, conflicting opinions on how to spell it are in a current debate, with two main schools of thought that each fall in line with one of two approaches that can be called the "word-based model" and the "base-word model." In my recent 2018 study published in English Today, I have attempted to show that, in writing down words that end with "shun," the base-word model is to be preferred over the word-based model, presenting argument for a synchronic rule with seven conditions to warrant the use of -sion as opposed to -tion, albeit with exceptions. In the present study I have attempted to establish the difficulty with the spelling of "shun" as a phenomenon that affects spellers globally especially Non-Native users and learners of English and thus worthy of addressing in grammar textbooks. Specifically, with field experience from Cameroon that corroborate literature on the problem of English spelling and online debates, I have demonstrated that spellers generally face problems with the spelling of shun-words with either the -tion or the -sion variant, and that given specific rules to follow, there can be great improvement in spelling them.

With these conclusions, the need for extensive research on the topic of English spelling arises. The first need, which is more general, is motivated by the demonstration that users of English can find it much easier to spell English words if wide ranging spelling rules are readily available to follow and be able to diminish the yoke of memorization. (Note 4) Down to specifics, note that the multiplicity of conditions in the BWB rule together with their exceptions actually means that further research is required for simpler rules. Then, in order to unequivocally conclude that the problem with the spelling of shun-words is actually a global phenomenon whose prevalence comes about due to the lack of established spelling rules for spellers to follow, a study similar to the present one with respect to the spelling test would be required elsewhere in the English speaking world to see if similar spelling preferences are recorded. Finally, with respect to the potential benefits of the BWB rule for spelling shun-words, it would be very important to conduct a complementary pilot study to see how students who receive instructions with the rule inclusive would perform at the spelling of shun-words, as opposed to those who do not receive such instructions.

\section{Acknowledgements}

I have discussed versions of this article with various sets of my postgraduate students in the Department of English at the University of Buea (Cameroon), and I am grateful for their comments. I am particularly grateful to my MA supervisees at the time of the study, Patience Ntain and Rodrick Lando for their role in grading the test scripts and painstakingly working out the statistics. The findings reported in this paper form part of an original study whose overall findings were originally submitted to English Today $(E T)$ and the other part published there. Thus, earlier versions of that original paper have been read at different times by Clive Upton and two anonymous ET reviewers for very helpful comments. Finally, I have benefitted from a semestral research allowance from the Faculty of Arts at the University of Buea, and a quarterly research modernization allowance from the Cameroonian Ministry of Higher Education for which I am grateful. 


\section{References}

Achiri-Taboh, B. (2017). The "ph" of English orthography; a digraph or a sequence of separate phonemes?: Responding to Alan S. Kaye. English Today, 33(4), 47-49. https://doi.org/10.1017/S0266078417000256

Achiri-Taboh, Blasius. (2018). English spelling: Adding $/ \int^{\ominus} \mathrm{n} /\left(\right.$ or $\left./ \mathrm{J}^{\ominus} \mathrm{n} /\right)$ to base-words and changing from -tion to -sion: Alleviating the yoke of memorization for English spellers. English Today, 1-7. https://doi.org/10.1017/S0266078417000591

Achiri-Taboh, B. \& Lando, Rodrick. (2017). English in Cameroon: Issues of Teacher Language Proficiency. International Journal of English Language Teaching, 4 (1), 20-31. http://dx.doi.org/10.5430/ijelt.v4n1p20

Adams-Gordon, B. L. (2010). The why \& how of teaching spelling. Pomeroy: Castlemoyle Books.

Akundayo, S. B. O. (2014: 4). Suggested spelling reform in Educated Nigerian English (ENE): Who bells the cat? SAGE Open, April-June: 1-14.

Allen, Robert. (2002). One Step Ahead: Spelling. Oxford University Press.

Bezrukova, M. K. (2003). What English do you need? Kareen's Linguistics Issues. Retrieved from http://www3.telus.net/linguisticsissues/index.html

Bilchik, Nadia \& Cole, Kat. (2012). Small Changes: Big Impact: Maximize your presence and leverage the power of your personal brand. Greater Impact, Atlanta, Johanessburg.

Bloomfield, L. (1934). Language (British ed.). Chicago, IL: UrwinBooks.

Crystal, D. (2005). The Cambridge encyclopedia of the English language (2nd ed.). Cambridge, UK: Cambridge University Press.

Firth, J. R. (1937). Tongues of men. London, England: Watts.

Harnew, M. (2007). Which suffix? -tion, -sion, -ssion or -cian? Online at <http://www.skillsworkshop.org/> (Accessed July 5, 2016)

Huddleston, Rodney \& Pullum, Geoffrey. (2005). A Student's Introduction to English Grammar. Cambridge University Press. https://doi.org/10.1017/CBO9780511815515

Jowitt, D. (2008, March 28). Varieties of English: The world and Nigeria (Inaugural lecture). Jos, Nigeria: University of Jos.

Kaye, A. S. (2006). Linguistic note on English orthography and current usage. English Today 22(1), 54-6. https://doi.org/10.1017/S026607840600109X

LearningExpress. (2006). Vocabulary and spelling success. LearningExpress, LLC, New York

Perrin, Robert. (1990). The beacon handbook. Houghton Mifflin Company, Boston.

Pinker, Steven. (1999). Words and Rules: The Ingredients of Language. New York: HarperColins.

Richards, R. F. (2002). Key Skills Level 1: Information technology, application of number and communication. Payne-Gallway Publishers Lt.

Saussure, Ferdinand. (1966). Course in General Linguistics. McGraw-Hill.

Seely, John. (2005). Oxford Guide to Effective Writing and Speaking (Second edition). Oxford University Press.

Shepheard, John. (2001). English grammar. McGraw-Hill Companies, Inc.

Taylor, D. S. 1981. English Spelling: a Help rather than a Hindrance. ELT J XXXV, (3), 316-21. https://doi.org/10.1093/elt/XXXV.3.316

Upward, Christopher \& George Davidson. (2011). The History of English Spelling. Malde, MA: Wily-Blackwell. https://doi.org/10.1002/9781444342994

West, Michael. (1955). English Spelling. ELT J IX, (4), 132-6. https://doi.org/10.1093/elt/IX.4.132

West, Michael. (1965). The problem of Spelling. ELT J XX, (1), 10-14. https://doi.org/10.1093/elt/XX.1.10

Woods, Andrew. (2004). Spelling Skills Builder Teacher Book. Oxford University Press.

Yule, V. (1991b). Spelling society. Available from www.Spellingsociety.org (unspecified access date)

<https://www.dailywritingtips.com/the-spellings-of-shun/> (accessed June 15, 2018) 
<https://howtospell.co.uk/tionwords> (accessed June 15, 2018)

<http://www.oxfordtoday.ox.ac.uk/features/what\%E2\%80\%99s-happening-english-spelling> (Accessed June 5, 2018)

<https:/www.quora.com/Why-do-so-many-seemingly-intelligent-people-have-such-a-problem-with-spelling-the-wo rd-lose-instead-writing-loose> (Accessed June 5, 2018)

<https://www.skillsworkshop.org/resources/words-ending-shun-sound> (accessed June 15, 2018)

<https://www.spellzone.com/unit28/page3.cfm> (Accessed July 5, 2016)

< http://theconversation.com/the-absurdity-of-english-spelling-and-why-were-stuck-with-it-44905> (Accessed June 5, 2018)

\section{Notes}

Note 1. My paper referred to here as Achiri-Taboh (2018) has actually been published as a 2018 online publication by English Today, and the paper is yet to appear in a printed issue of the journal with hardcopy page references.

Note 2. The seven conditions are summarized here as follows: A: the base-word ends with a $d(e)$; or B: with any of the stressed syllables -fuse, -vert; or C: the syllable -pel; or D: the base-word is a disyllabic word that ends with the syllable $-C+$ ise $(C$ being any consonant); or E: a word that ends with the stressed final syllable $-m i t$; or F: the stressed final syllable -cedel-ceed; or G: the base-word ends with a double-s.

Note 3. Akundaye recollects a chunk of the criticism, starting with Crystal's (2005: 215) citation that "in 1151, John Hart complained of the 'vices' of English writing, which cause it to be 'learned hard and evil to read'." Saussure (1966: 23, 31) call the English spelling system "an edifice of confusion," "inconsistencies," and "monstrosities." Bloomfield (1934) claim that the English writing system is conservative and some word spelling archaic and so ingrained that people are reluctant to reform them, and points out (p. 292) that "Sounds which existed when our spelling became habitual, but have since been lost by linguistic change, are still represented in our writing by silent letters, as in name, know, gnat, bought, would." Firth (1937: 48) also state that "English spelling is so preposterously unsystematic that some sort of reform is undoubtedly necessary in the interest of the whole world." Jowitt (2008: 1) reechoed Firth's statement by observing that the vocabulary of English "is vast and constantly expanding, but its grammar contains many anomalies and its spelling is notoriously irregular. Perhaps one day the international community will insist on its reform." Bezrukova (2003), in a view held by Yule (1991), describes English spelling as being "so hopeless at representing phonemes that a reform based on virtually any accent would be an improvement for everyone elsewhere."

Note 4. Note that teachers of English and other subjects taught in English are certainly not spared the trouble of having to spell accurately. In a 2017 study that accesses the spelling skills of 40 ESL teachers of public secondary schools in the Tiko and Buea Subdivisions of the Southwest Region of Cameroon selected by means of the Homogenous Purposive Sampling Technique (see Achiri-Taboh \& Lando, 2017), 36 were found to exhibit spelling difficulties with many words in the required writing wrongly spelled. 